\title{
Fundamental factors related to continuing education in family nursing in Japan: A mixed methods approach
}

\author{
Akemi Yamazaki \\ Department of Nursing, Faculty of Human Sciences, Sophia University, Tokyo, Japan. \\ Correspondence: Akemi Yamazaki. Address: Department of Nursing, Faculty of Human Sciences, Sophia University, \\ Tokyo, Japan. Email: akemiyamazaki@sophia.ac.jp
}

Received: September 12, 2013

Accepted: October 28, $2013 \quad$ Online Published: December 15, 2013

DOI : $10.5430 /$ jnep.v4n1p247

URL: http://dx.doi.org/10.5430/jnep.v4n1p247

\begin{abstract}
In medical settings in Japan, where $25 \%$ of the total population is aged $\geq 65$ years, an emphasis has been placed on homecare. Accordingly, nurses face the urgent task of interacting effectively with patients' families, who are in a position to provide care for patients, in addition to the patients themselves. The aim of the present study was to obtain suggestions for continuing education that promote the practical family nursing ability of generalist nurses at medical facilities in Japan.

A mixed methods approach was used to survey continuing education in family nursing in Japan. At 1,000 facilities accredited by the Japan Council for Quality Health Care, the implementation of lecture-style, in-house group training and its fundamental characteristics were explored through a questionnaire survey and interviews. Facilities with many hospital beds and personnel in charge of education conducted lecture-style, in-house group training on family nursing. The following four fundamental characteristics were identified: (1) an organizational culture of "the family as the target of nursing"; (2) the belief that "the patient lives at home"; (3) experience of "being useful to the family"; and (4) structures for "intersection of learning and teaching”.

In summary, the study suggests the need to allocate personnel in charge of continuing education and, where this may be difficult, as in small- and medium-sized facilities, to adopt guidelines on continuing education through on-the-job training using the four fundamental characteristics identified in this study.
\end{abstract}

\section{Key words}

Continuing education, Family nursing, Mixed methods approach

\section{I ntroduction}

Family nursing care is a systematic approach in which nursing personnel promote the improvement of the health of a family member, a subsystem, or a family system by identifying health-related problems and goals in a number of specialized fields. The key theoretical bases for the implementation of family nursing care are systems theory, developmental theory, and structural functional theory ${ }^{[1-3]}$. For example, nursing professionals such as certified nurse specialists (CNSs) who have undertaken training in family nursing at the Master's degree level can use such theoretical bases to systematically understand what occurs in the patient-family-medical professional relationship. Furthermore, they can engage in practices that promote development of the relationship between the ailing patient and the family. 
In a survey administered to members of the Japanese Association for Research in Family Nursing by Torii et al ${ }^{[4]}$, 95\% of respondents replied that the family was the target of nursing. On the other hand, almost the same number of respondents thought that they did not have the power to influence families, and that they did not deal with them fully. Furthermore, circumstances surrounding families and medical care in Japan in recent years make the situation even more complex in certain respects. First, the shrinking of household size in recent years has been striking, and it is not a simple matter of expecting families to provide care. Second, added to this is the Second Rationalization of Medical Expenses Plan (2013-2017) formulated by the Ministry of Health, Labour and Welfare. Namely, this is a recently adopted plan for handling the falling birthrate and ageing society; it will restrict medical costs and provide community-based medical care. This plan aims to cut the number of total hospital beds by approximately 430,000 and reduce the number of inpatients by 330,000 (approximately 20\%) per day. These measures are linked to the shortening of the length of patients' hospital stay, but the majority of inpatients are elderly, and many of them still require medical care and assistance with daily living even after they are discharged from the hospital. What this means is that the families who must provide care, which has become more difficult at present, face an even greater burden when these patients leave the hospital ${ }^{[5-6]}$. A mid this upheaval, many generalist nurses struggle to handle the family during the patient's hospitalization or at the time of discharge.

Japan has CNSs for family health nursing, and they undergo practical training in family intervention, as well as learn theories that form the basis of family nursing care in Master's degree programs. However, as of April 2013, only 21 nurses held this qualification ${ }^{[7]}$. Thus, many cases in medical settings nationwide are handled by generalist rather than specialist nurses. In Japan, there are currently 1.3 million nurses working, the majority of whom are generalist nurses who have graduated from vocational schools, junior colleges, or universities. While there is a nurse certification renewal system for CNSs and certified nurses in Japan as in other countries, there is no such system for generalist nurses.

\section{Continuing education in family nursing care}

The importance of continuing education in family nursing care has been discussed since the $1990 \mathrm{~s}^{[8-10]}$. There have been various reports from individual facilities ${ }^{[11-13]}$. According to joint multi-facility reports, six universities in the United States and Europe adopted a jointly developed, web-based, family nursing accreditation program ${ }^{[14]}$, while universities in Scotland and Finland provided two-year continuing education in accordance with the WHO family health nurse project and carried out subsequent evaluations ${ }^{[15,16]}$.

Continuing education for the nursing profession has also been promoted in Japan. In recent years, new guidelines were released by the Ministry of Health, Labour and Welfare for new recruit training ${ }^{[17]}$. Such training for newly qualified nurses has established a base for implementing workplace education with standardized content nationwide. However, many issues in relation to other forms of continuing education remain. All facilities, regardless of size, have an organized education committee within the nursing department. A committee member who plans and manages annual training programs is elected from each ward.

The quality of continuing education in family nursing care depends on the approach of each facility, academic society, or study group. At the same time, such approaches also possess the following unifying characteristics. First, since education in family nursing is not part of the core curriculum in undergraduate education in Japan, the hours spent and content included vary widely depending on the school. For this reason, it is often required as part of continuing education after graduation. However, second, any educational strategies by which academic family nursing research findings can be used in practice, as explored in previous studies ${ }^{[18,19]}$, are often regarded as something intangible and highly variable or difficult to carry out and evaluate in training, compared to education in specific nursing care and techniques for individual patients.

With respect to continuing education regarding family nursing care in Japan as it stands now, researchers are able to observe certain approaches at individual facilities. However, the type of education actually being conducted and the components deemed crucial for continuing education in family nursing have yet to be reported. 


\section{Theoretical nursing framework of continuing education in family nursing care}

Continuing education is a broad concept that includes lifelong learning after graduation from educational institutions. Lecture-style, in-house group training offered to nurses at hospitals and clinics is one example. Benner and Wrubel explained the difference between knowing how (practical knowledge through skilled practice) and knowing that (theoretical knowledge ${ }^{[20]}$. Knowledge necessary for nursing includes practical knowledge and theoretical knowledge, the latter being the focus of attention in this study of family nursing. Within this context, there has been debate regarding the importance of training to bridge the gap between theory and practice in theoretical knowledge ${ }^{[21-24]}$.

In order to acquire theoretical knowledge, adult learning, which includes recognition of the grounds and assumptions of one's own beliefs and the ability to implement radical changes of mentality where necessary, is required. That is, the learning cycle of reviewing and reflecting on one's own practice fosters this theoretical knowledge ${ }^{[25]}$. Since it is difficult to do this alone, a safe environment in which to be aware of this thinking needs to be established. However, in hospital on-the-job education programs, the design and management of this kind of knowledge seem to be more difficult than training for the acquisition of practical knowledge ${ }^{[26]}$.

Within this context, this study focused on continuing education in family nursing, exploring the components that lead to developing theoretical knowledge through on-the-job-training, as well as ascertaining the lecture-style, in-house group training of today.

\section{Study aim}

(1) To ascertain the number of facilities implementing family nursing off-the-job education programs (such as lecture-style, in-house group training) and to clarify the features of facilities conducive to the implementation of family nursing in-house group training.

(2) To explore fundamental characteristics necessary for staff development to facilitate the implementation of family nursing care in on-the-job training in medical facilities in Japan from the perspective of nursing professionals.

\section{Methods}

The research design used mixed methods ${ }^{[27,28]}$, similar to previous studies concerning the establishment of educational methods for emerging theoretical knowledge ${ }^{[29]}$. For the following reasons, both qualitative and quantitative methods, utilizing simultaneous triangulation within a mixed methods approach ${ }^{[30]}$, were used in this study.

Within the field of continuing education in family nursing, this study focused specifically on training in theoretical knowledge to link theory and practice in family nursing. Accordingly, the study used induction to explore issues arising in on-the-job training, as well as the implementation of off-the-job training such as lecture-style, in-house group training. Based on this premise, as well as identifying features of facilities that are implementing lecture-style, in-house group training through quantitative methods, it seemed effective to qualitatively explore ways in which facilities not currently implementing group training in family nursing were engaged in education in this area within the normal course of work, looking at the factors that form the base of practice.

For study aim (1), a questionnaire survey was conducted to investigate current lecture-style, in-house group training on family nursing. For study aim (2), the researcher conducted an in-depth interview to explore characteristics that influence the effectiveness of continuing education in family nursing care for generalist nurses.

\section{Ethical considerations}

The project was approved by the Research Ethics Committee of the researcher's agency (No 2823). The quantitative survey was anonymous and collected by mail. For the qualitative survey, when interview data were transcribed verbatim, 
any information identifying the individual was deleted or encoded. Interviews were conducted one-on-one, with the educator participating in the research in a private room, and the verbatim transcripts were not disclosed to anyone else.

\section{Samples and sampling}

Of the 2,578 facilities that were accredited in hospital function evaluations by the Japan Council for Quality Health Care, the researcher conducted a quantitative survey of 1,000 facilities by stratified sampling of five different geographic areas. The questionnaires were mailed to the head of the nursing care department of each facility, and nurses in charge of education were asked to complete the survey. Respondents were asked to complete the survey anonymously and, as a sign of agreement, send it back.

Also enclosed was a return postcard asking respondents to participate in a separate interview survey. The researcher later visited nurses in charge of education at 40 facilities who had agreed to complete the interview survey, regardless of whether they were currently conducting family nursing training. The questionnaire data collection and analysis occurred from December 2009 through October 2010, and the interview data were collected from December 2010 through April 2011.

\section{Quantitative survey}

The researcher inquired about facility and survey respondent attributes. Question items related to family nursing care training were designed through a literature search on methods and forms of continuing education in family nursing, searching Medline and Japan Medical Abstracts databases with the keywords "family nursing”, "continuing education”, and "educational program". University lecturers teaching family nursing studies were asked to check content validity, and a pretest was conducted with 3 nursing professionals working on education committees in medical facilities.

\section{Qualitative survey}

For the in-depth interview, the researcher visited individual facilities and conducted private interviews with nurses in charge of education. Written, informed consent was sought and obtained from all participants. To explore the characteristics that are fundamental to continuing education in family nursing, the researcher began by asking the nurses about difficulties in dealing with families, the kind of nursing care they provide to families, and what they hoped to see families being able to do. The researcher then asked, "What learning methods can achieve that goal?" and "What are the factors fundamental to continuing education to prepare nurses to provide family nursing care?” With the consent of the interviewees, verbatim transcripts were made from the tape-recorded interviews.

\section{Analysis}

Descriptive statistics were calculated from the quantitative survey contents, and the facility characteristics that affected the implementation of family nursing training were examined via logistic regression analysis with training-implementation as a dependent variable. Analysis of the data was performed with the Statistical Package for the Social Sciences, Windows version 17.0 (SPSS, Chicago, IL).

Concerning the qualitative survey, the researcher performed qualitative induction on the content analysis to identify content and methods that support effective continuing education for family nursing care ${ }^{[27]}$. Content analysis involves selecting themes through coding and categorizing text accounts ${ }^{[31,32]}$. This technique was used as a means of extracting common themes from qualitative data obtained from facilities that differed in their characteristics.

The interviews were recorded on tape, transcribed, and read. All fragments that appeared to be relevant in answering the research questions were provided with keywords that were derived by induction from the interview material. Then, the interview fragments were compared with fragments with the same keywords in previous interviews. Following the analysis, some participants were asked to check the accuracy of the researcher's interpretations ${ }^{[33]}$. 


\section{Results}

\section{Attributes (facilities and respondents)}

Table 1 shows the respondents' attributes, and Table 2 shows the facility attributes and the state of in-house education from the quantitative survey responses. The survey recovery rate was $31.6 \%$. Questionnaires on hospital attributes that did not contain more than $1 / 3$ of the total responses were removed; the valid response rate was $28.9 \%$.

Table 1. Characteristics of the respondents to the quantitative survey

\begin{tabular}{ll}
\hline Characteristic & Overall $(\mathbf{N}=\mathbf{2 8 9})$ \\
\hline Age (years, mean \pm SD) & $49.72 \pm 7.45$ \\
Sex (female) $n(\%)$ & $292(91.3)$ \\
$\quad$ Clinical experience (years, mean \pm SD) & $26.89 \pm 7.54$ \\
Time in charge of educational committee (years, mean \pm SD) & $4.85 \pm 4.86$ \\
Title $n$ (\%) & $70(24)$ \\
$\quad$ Nursing department director & $25(8)$ \\
Nursing department assistant director & $88(31)$ \\
Head nurse on education committee & $106(37)$ \\
Education committee member & \\
Educational background $n(\%)$ & $227(79)$ \\
Diploma school & $25(10)$ \\
Junior college & $9(3)$ \\
Undergraduate & $28(8)$ \\
Graduate &
\end{tabular}

Table 2. Facility characteristics $(\mathrm{N}=289)$

\begin{tabular}{|c|c|c|c|c|}
\hline Characteristic (Range) & $\begin{array}{l}\text { Total }(\mathbf{n}=\mathbf{2 8 9}) \\
\text { mean } \pm \text { SD or } n\end{array}$ & $\begin{array}{l}\text { Group } 1(\mathbf{n}=53) \\
\text { mean } \pm \text { SD or } n(\%)\end{array}$ & $\begin{array}{l}\text { Group } 2(\mathbf{n}=\mathbf{2 3 6}) \\
\text { mean } \pm \text { SD or } n(\%)\end{array}$ & $\boldsymbol{P}$ \\
\hline Number of hospital beds (40-1130) & $300.93 \pm 205.09$ & $355.86 \pm 231.25$ & $288.89 \pm 197.40$ & $*$ \\
\hline \multicolumn{5}{|l|}{ Hospital classification } \\
\hline Specific function & 16 & $2(12.5)$ & $14(87.5)$ & \multirow[b]{2}{*}{ ns } \\
\hline Others & 273 & $51(18.7)$ & $222(81.3)$ & \\
\hline Number of nursing staff (24-1180) & $227.65 \pm 185.21$ & $271.36 \pm 199.31$ & $218.00 \pm 180.95$ & ns \\
\hline Average tenure of nursing staff (2.4-40.0) & $9.13 \pm 4.32$ & $9.77 \pm 4.80$ & $9.00 \pm 4.21$ & ns \\
\hline \multicolumn{5}{|l|}{ Patient-nurse ratio } \\
\hline $7: 1$ & 146 & $31(21.2)$ & 115 (78.8) & \multirow[b]{2}{*}{ ns } \\
\hline Others & 143 & $22(15.4)$ & $121(84.6)$ & \\
\hline Number of new nursing staff in the last year $(0-150)$ & $22.31 \pm 24.16$ & $26.26 \pm 28.00$ & $21.45 \pm 23.29$ & $n s$ \\
\hline \multicolumn{5}{|l|}{ Average length of hospital stay } \\
\hline More than 16 days & 155 & $33(21.3)$ & $122(78.7)$ & \multirow{2}{*}{ ns } \\
\hline Less than 16 days & 134 & $20(15.0)$ & $114(85.0)$ & \\
\hline \multicolumn{5}{|l|}{ Presence of a discharge support department } \\
\hline Yes & 253 & $53(20.9)$ & 200 (79.1) & \multirow[t]{2}{*}{$*$} \\
\hline No & 36 & $0(0)$ & $36(100)$ & \\
\hline \multicolumn{5}{|l|}{ Presence of full-time personnel in charge of education } \\
\hline Yes & 194 & $51(26.3)$ & $143(73.7)$ & \multirow[t]{2}{*}{$*$} \\
\hline No & 95 & $2(2)$ & $93(98)$ & \\
\hline Number of education committee meetings (2-35) & $13.04 \pm 6.11$ & $15.34 \pm 5.68$ & $12.51 \pm 6.11$ & $*$ \\
\hline Number of education committee members (1-48) & $10.52 \pm 5.26$ & $11.61 \pm 5.93$ & $10.34 \pm 5.08$ & ns \\
\hline \multicolumn{5}{|l|}{ Training during working hours } \\
\hline Yes & 97 & $16(16.5)$ & $81(83.5)$ & \\
\hline No & 192 & 37 (19.3) & 155 (80.7) & $n s$ \\
\hline
\end{tabular}

Notes. Group 1: The facilities have conducted group training in family nursing. Group 2: The facilities have not conducted group training in family nursing.

$*, p<.05$, $t$-test or $\chi^{2}$ test

Published by Sciedu Press 


\section{Lecture-style, in-house, group training in family nursing care}

The results showed that 53 facilities (18\%) had conducted group training in family nursing. According to the multipleanswer breakdown, more than $80 \%$ had their staff participate in out-of-hospital training on family nursing and then conduct lectures for their colleagues. More than $60 \%$ responded that family nursing is included in other lecture-style, in-house, group training, such as discharge coordination, critical care nursing, and cancer nursing care training. Less than $20 \%$ had conducted lecture-style, in-house, group training under the course name of family nursing care; only $4 \%$ had a family nursing course in the annual in-house training plan.

\section{Facility characteristics associated with lecture-style, in-house group training}

After dividing the respondents into two groups (those who had conducted family nursing training and those who had not), a univariate analysis of correlation (either a chi-square test or a $t$-test) was conducted. A positive correlation of $p<.05$ was observed for the following four characteristics: number of hospital beds; the presence of a discharge support department; the presence of full-time personnel in charge of education; and the number of education committee members.

Of the facility characteristic items of the quantitative survey in Table 2, a logistic regression analysis was conducted assuming those showing a correlation of $p<.05$ on univariate analysis to be independent variables and the presence of group training implementation in family nursing to be a dependent variable. As Table 3 shows, at facilities where there were many hospital beds and personnel in charge of education, in-house group training on family nursing had been conducted.

Table 3. Facility characteristics related to the implementation of group training

\begin{tabular}{lllll}
\hline Variable & $\beta$ & OR & 95\%CI & $\boldsymbol{p}$ \\
\hline Number of hospital beds & 0.02 & 1.002 & $1.000-1.003$ & .037 \\
Personnel in charge of education & 2.685 & 14.664 & $3.458-62.182$ & .000 \\
\hline
\end{tabular}

Notes. Hosmer - Lemeshow test $\quad \mathrm{x}^{2}=3.197, \mathrm{df}=8 . p=.921$

Model test, $\mathrm{x}^{2}=47.574, \mathrm{df}=3 . p=.000 \quad 81.3 \%$

\section{Various fundamental factors related to continuing education in family nursing care}

From December 2010 through April 2011, an in-depth interview with nurses at 40 facilities who had been involved in in-house education was performed. With the consent of the interviewees, verbatim transcripts were made from the tape-recorded interviews. There were up to five participants depending on the facility, such as the nursing department director, nursing department assistant director in charge of education, head nurse, and a nurse from the education committee. Interviews ranged in length from 40 to 95 minutes (average, 65 minutes). Table 4 shows the respondents' attributes. From the interview responses, the researcher identified four characteristics as being essential in continuing education to acquire the skills needed in family nursing care in Japan. The details of these characteristics, which would also be fundamental in promoting education as part of daily on-the-job training, are as follows:

(1) Organizational culture in which "the family is the target of nursing care"

Depending on the ward, the admission period is short, and on some wards there is hardly any chance to meet the family. On such wards, it's a matter of talking (to the family) on the phone, or catching them when they come to visit, but very little time is spent actually involved with them. It's important to make staff aware that nursing care is for the family." (Assistant Director of Nursing Department in charge of education, advanced treatment hospital)

As can be seen here, engagement with families is limited in some situations in which nurses work. In such cases, it was claimed that it is not possible to implement the principle of "the family as the target of nursing care" effectively in a short 
time, unless this kind of culture was explicitly fostered. In contrast, as in the following extract, where nurses work routinely with families, this organizational climate is developed as a matter of course among all staff on the ward at all times.

Since the goal of this facility (convalescent rehabilitation hospital) is to send the patient back to his or her home, it's imperative that you get involved with the family. Such a climate is necessary before education. (Head Nurse in charge of education, convalescent rehabilitation hospital)

It is meaningless to dogmatically repeat the statement, "Family nursing care is important." Rather, if you clarify what nurses need to do to be involved with families in the course of their actual duties and if there is a role model in the team, it will be easy to see what should be learned.

(2) The belief that "the patient lives at home"

If you basically believe that the person should be living at home with the family even if they become ill, you start to always think about how that person would be living in their home with their family. Some members of staff don't have that awareness. (Head Nurse, general hospital)

As described above, if the nurse thinks of the patient living at home with the family as a basic foundation, consciousness of how the patient would be spending time at home, the issues that could present difficulties after returning home, and the opinions and thoughts of the family emerge naturally. Nurses should be trained so that they will develop a broad perspective, not just for the patients inside their facility, but also beyond.

I want young people to know that the patient and the family live in a circle. Once they start asking questions such as 'Why are they hospitalized now?' and 'Where do they go after being discharged from the hospital?' their family nursing care will come more naturally. (Head Nurse in charge of education, general hospital)

(3) Experience of "being useful to the family"

Saying, 'Let's study family nursing care,' does not get you anywhere. Instead, in the course of actual nursing duties, you should create more opportunities to focus not only on the patient but also on his or her family. (Education Committee member, general hospital)

As described above, it was considered important to build up experience by contributing through intervention in actual cases. Since every family is different, there is a limit to what classroom lectures (such as lecture-style group training) can achieve. Thus, people at all facilities commented that it is desirable to provide opportunities to assess and intervene with the family through individual case examples.

In reality, the results of nursing care for the family are often not immediately apparent. It's important to reflect on them through conferences and so on. (Education Committee Member, psychiatric hospital)

For example, difficult cases are often presented during the committee activity of continuing nursing or nursing ethics or at joint multi-professional conferences. In such cases, not only the patient but also the family might have a strong influence. Thus, through such cases, nurses can acquire the ability to carefully examine different issues.

(4) Structures for "interaction of learning and teaching"

We don't have an education committee member with the capability to teach family nursing systematically through group training or suchlike here. But in the actual course of work, senior nurses do manage to communicate this to their junior colleagues. (Head Nurse, general hospital) 
Many facilities proudly claim that their new-recruit and nursing-technique training are effective and on target. However, aside from family nursing, training to teach theory and ethics has often been riddled with problems in planning and management. It was desirable that they consider these problems while training newcomers. For example, one facility said that they would like to actively recruit and train personnel with five years of clinical experience as education committee members in training, planning, and management. The importance of having an interactive process of learning and teaching between nurses was pointed out.

I want to train nurses of a certain mature age - those who can do a solid job-to have the information from the family and work jointly as a team so that they can lead younger staff members. (Head Nurse, general hospital)

Table 4. Characteristics of the respondents to the qualitative survey

\begin{tabular}{ll}
\hline Characteristic & Overall $\mathbf{( N = 7 5 )}$ \\
\hline Age (years, mean \pm SD) & $35.62 \pm 6.50$ \\
Sex (female) $n(\%)$ & $73(97)$ \\
Clinical experience (years, mean \pm SD) & $12.88 \pm 7.05$ \\
Time in charge of educational committee (years, mean \pm SD) & $4.05 \pm 4.00$ \\
Title $n(\%)$ & \\
Nursing department director & $10(13)$ \\
Nursing department assistant director & $22(30)$ \\
Head nurse on education committee & $9(12)$ \\
Education committee member & $22(30)$ \\
Staff nurse & $8(10)$ \\
Others (e.g. MSW, Care worker) & $4(5)$ \\
Educational background $n$ (\%) & $32(43)$ \\
Diploma school & $21(28)$ \\
Junior college & $10(13)$ \\
Undergraduate & $12(16)$ \\
Graduate &
\end{tabular}

* The total number of participants was 75 from 40 facilities.

\section{Discussion}

The scale of the facility directly influenced the quality and quantity of lecture-style, in-house, group training. The results of the quantitative survey reveal that it is possible to adopt in-house, lecture-style, group training when the scale of the facility is large. By contrast, the training menu at facilities with a single department or fewer nursing units is very limited, meaning that they have little latitude for family nursing. Some programs mentioned in documents from other countries show that they involve several weeks and several units ${ }^{[14-16]}$. By comparison, it is difficult for a single facility to independently conduct training because of cost and personnel.

Similar to examples from other countries, lecture-style, in-house group training could cover training in skills of communication with families and learning what systems theory is and so on. However, lecture-style, in-house, group training is not the only ideal learning style. It is not only a matter of acquiring knowledge-the important thing is training to attach theoretical meaning to practical experience and practical skills to link abstract family theory and family practice in real situations ${ }^{[26]}$. It helps to clarify the points to realize the theoretical premise of this study, that the learning cycle of reviewing and reflecting on one's own practice fosters this theoretical knowledge, in on-the-job training. Thus, the researcher extracted the following points as four fundamental factors for continuing education.

First, family nursing is based on family-oriented thinking, and the patient's family is part of nursing care. The importance of "an organizational culture in which "the family is the target of nursing care" emerged in this study. Yet, for example, as pointed out by St John and Flowers based on their qualitative research findings ${ }^{\text {[34] }}$, there is a gap in family nursing 
education and mentorship depending on the practice site. In a ward for seriously ill patients, nurses tend to be thoroughly trained and blessed with an educational environment; however, this is exactly what is lacking in wards with a high turnover rate. From the data in this study, too, it seems that, on wards where the family is always being dealt with, seeing the family as the target of nursing care is part of the natural training of everyday work, while specific measures and strategies are necessary on wards where this is not the case.

The second main factor was "the belief that 'the patient lives at home'”. Families live in society. There are many structures in society supporting people's lives, such as the nation, community, neighborhood, workplace, and school. What happens in medical institutions is only one part of the life of the patient and family, and it is necessary to constantly expand the sphere of vision to encompass the life of the patient and family in society ${ }^{[1]}$. Instead of focusing solely on the medical condition of the patient, the nurse should conduct nursing care while envisioning the place where the patient used to live until hospitalization or their future residence after discharge. To do so, the nurse must have a keen interest in the living conditions of the patient with his or her family members.

The third characteristic is "experience of 'being useful to the family'”, and here the key is to provide nurses with opportunities to assess and interact with the family through specific case examples. There are various methods of continuing education in nursing. In this survey, the necessity to convey specific advice to staff in the course of actual duty was stressed. For example, one may specifically explain to the staff at a joint multi-professional conference, "This is exactly how you can assess and interact with the family." Transmitting experiential knowledge not only in the course of work, but also through systematic training, serves to develop many nursing professionals. In other countries, for the purpose of familiarizing nursing staff with assessment and intervention models, innovative content and methods have been adopted in training programs ${ }^{[14-16]}$. Such forms of systematic group education may be valuable if combined effectively with current education.

The fourth characteristic is "structures for intersection of learning and teaching”, which involves having teaching-learning interactions and interaction among nurses. It is important to nurture human resources capable of providing sage guidance to junior staff and leading the team, as opposed to being passive and inactive. It is about generating teaching-learning interactions among nurses. Duhamel pointed out that the key task is to meld the wisdom of family nursing science with that of clinical medicine ${ }^{[19]}$. The results of this survey suggest that helping the nursing team to develop will also have positive synergistic effects on the patient and family.

Suggestions for continuing education for family nursing at medical facilities in Japan can be summarized as follows.

First, the target level for generalist nurses is implementation of family nursing from the perspective of family as context as indicated by Bomar ${ }^{[35]}$. The first two of the four characteristics identified in the present study describe examples of this nursing care in a clear manner; specifically, they demonstrated the point about on-the-job training emphasizing family nursing theory on family-oriented thinking and on the community rather than hospitals as the basis of daily life for patients and their families.

Second, the last two characteristics identified in the present study, which demonstrated the sense of being useful to families and of promoting adult learning through mutual learning with colleagues, were identified as strategies for cultivating the theoretical knowledge of generalist nurses in on-the-job training. Leahey et al. stated five premises that should be the core of the family-nurse relationship in practice ${ }^{[9]}$. One is the importance of understanding the feedback function, which is to say that the relationships among the nurse, the family, and other systems are being generated simultaneously. In other words, the nurse needs to develop a systemic perspective. Therefore, in training for the theoretical knowledge of generalist nurses in on-the-job training, family nursing specialists (CNS, FNP), who are the practitioners of systems theory, may be expected to take leadership. 


\section{Conclusion}

The limitation of the present study was that the response rate was only around $30 \%$. This was attributed to the fact that many medical facilities have yet to engage in in-house group educational programs on family nursing, which may have made subjects hesitant to respond. Therefore, the present results may be predicted to have been biased toward groups with a strong interest in continuing education for family nursing. However, no other nationwide surveys on this topic exist, and the present data were considered valuable for advancing Japanese healthcare, which emphasizes nursing care for families.

Only $17 \%$ of the surveyed facilities had implemented lecture-style, in-house, group training and seemed to fully comprehend the need for continuing education in family nursing in Japan. These were also large-scale facilities with a nurse in charge of in-house education. The in-depth interview results suggested four fundamental characteristics of on-the-job training. The present findings identified factors that are fundamental in continuing education in Japanese family nursing.

\section{Acknowledgments}

The present study was supported by a Grant-in-Aid for Scientific Research (C) (No.21592687) from the Ministry of Education, Science, Sports and Culture of Japan.

\section{References}

[1] Friedman MM, Bowden VR, Jones EG. Family Nursing: research, theory, and practice. 5th ed. New Jersey: Prentice Hall. 2003; 59-170.

[2] Kaakinen JR, Hanson SMH. Theoretical foundations for family health nursing practice. In: Bomer PJ (ed). Promoting health in families: applying family research and theory to nursing practice. 3rd ed. Philadelphia: Saunders. 2004; 93-116.

[3] Kaakinen JR, Hanson SMH. Theoretical foundations for the nursing of family. In: Kaakinen JR, Deborah DP, Gedaly-Duff V, Bomer PJ (eds). Family health care nursing: Theory, practice and research. 4th ed. Philadelphia: FA Davis. 2010; 63-102.

[4] Torii H, Mori H, Sugishita T. Kanngosya no kazokukanngonituite no ninnshiki [Recognition about family nursing for nurse]. J. Acad. Fam. Nurs. 2004; 9(3): 113-122.

[5] Ministry of Health, Labor and Welfare Statistics Association. Kousei hakusyo. [The Annual Report on Health, Labor and Welfare]. Tokyo: Ministry of Health, Labor and Welfare Statistics Association, 2011.

[6] Ministry of Health, Labor and Welfare Statistics Association. Zusetsu Kokumin Eisei no Doukou. [Health and Welfare statistics in Japan]. Tokyo: Ministry of Health, Labor and Welfare Statistics Association, 2011.

[7] Japanese Nursing Association. Certified nurse specialist. Available from: http://nintei.nurse.or.jp/nursing/qualification/cns

[8] Hanson S, Heims M, Julian D. Education for family health care professionals: Nursing as a paradigm. Fam. Relat. 1992 ; 41 : $49-53$. http://dx.doi.org/10.2307/585392

[9] Leahey M, Harper-Jaques S, Stout L, Levac AM. The impact of a family systems nursing approach: nurses’ perceptions. J. Continuing Educ. Nurs. 1995; 26: 219-225.

[10] International Council of Nurses. Standards and Competencies Series: ICN Framework and Core Competencies for the Family Nurse. Switzerland: International Council of Nurses, 2003.

[11] Goudreau J, Duhamel F, Ricard N. The impact of a family systems nursing educational program on the practice of psychiatric nurses: a pilot study. J. Fam. Nurs. 2006; 12: 292-306. PMid:16837696 http://dx.doi.org/10.1177/1074840706291694

[12] Tisher TB, Dean S, Tisher M. Aged care residential facility and family interface: a training program for staff. Clin. Gerontologist. 2009; 32: 309-323. http://dx.doi.org/10.1080/07317110902895952

[13] LeGrow K, Rossen BE. Development of professional practice based on a family systems nursing framework: nurses’ and families’ experiences. J. Fam. Nurs. 2005; 11: 38-58. PMid:16287817 http://dx.doi.org/10.1177/1074840704273508

[14] Anderson KH, Friedemann M. Strategies to teach family assessment and intervention through an online international curriculum. J. Fam. Nurs. 2010; 16: 213-233. PMid:20407002 http://dx.doi.org/10.1177/1074840710367639

[15] Murray I. Family health nursing: the education programme for the WHO Europe Scottish Pilot. Brit. J. Community Nurs. 2004; 9: 245-250. PMid:15269645

[16] Murray I. Family Health Nurse project-an education program of the world health organization: the University of Stirling experience. J. Fam. Nurs. 2008; 14: 469-485. PMid:19066336 http://dx.doi.org/10.1177/1074840708327965 
[17] Japanese Nursing Association. Shinjinkanngosyokuinnrinnsyoukennsyuu niokeru kennsyuusekininnsya kyouuikutanntousyaikuseinotameno Kennsyuugaido [Guideline for educator of new recruit training] Tokyo: Japanese Nursing Association Publishing Company, 2010.

[18] Leahey M, Svavarsdottir EK. Implementing family nursing: how do we translate knowledge into clinical practice? J. Fam. Nurs. 2009; 15: 445-460. PMid:19783792 http://dx.doi.org/10.1177/1074840709349070

[19] Duhamel F. Implementing family nursing: how do we translate knowledge into clinical practice? Part II: The Evolution of 20 years of teaching, research, and practice to a center of excellence in family nursing. J. Fam. Nurs. 2010; 16: 8-25. PMid:20145284 http://dx.doi.org/10.1177/1074840709360208

[20] Benner P, Wrubel J. Skilled clinical knowledge: The value of perceptual awareness. Nurs. Educator. 1982 ; 7: 11-17. http://dx.doi.org/10.1097/00006223-198205000-00003

[21] Benner P, Tanner CA, Chesla KA. Expertise in nursing practice: caring, clinical, judgment, and ethics. New York: Springer, 2009.

[22] Benner P, Sutphen M. Learning across the professions: the clergy, a case in point. J. Nurs. Educ. 2007; 46: 103-108. PMid:17396548

[23] Hatlevik IKR. The theory-practice relationship: reflective skills and theoretical knowledge as key factors in bridging the gap between theory and practice in initial nursing education. J Adv. Nurs. 2012; 68(4): 868-877. PMid:21790737 http://dx.doi.org/10.1111/j.1365-2648.2011.05789.x

[24] Christensen M. Advancing nursing practice: redefining the theoretical and practical integration of knowledge. J. Clin. Nurs. 2011; 20: 873-881. PMid:21320209 http://dx.doi.org/10.1111/j.1365-2702.2010.03392.x

[25] Kolb DA. Experiential learning, New Jersey: Prentice Hall, 1984; 39-42.

[26] Peden-McAlpine C, Tomlinson PS, Forneris SG, Genck G, Meiers SJ. Evaluation of a reflective practice intervention to enhance family care. J Adv. Nurs. 2005; 49(5): 494-501. PMid:15713181 http://dx.doi.org/10.1111/j.1365-2648.2004.03322.x

[27] Cresswell JW, Plano Clark VL, Gutmann ML, Hanson WE. Advanced mixed methods research designs. In Abbas T, Charles T (eds.). Handbook of mixed methods in social \& behavioral research. London: Sage Publications, 2003; 209-240.

[28] Foss C, Ellefsen B. The value of combining qualitative and quantitative approaches in nursing research by means if method triangulation. J Adv. Nurs. 2002; 40(2): 242-248. PMid:12366654 http://dx.doi.org/10.1046/j.1365-2648.2002.02366.x

[29] Blakely G, Skirton H, Cooper S, Allum P, Nelmes P. Use of educational games in the health professions: A mixed-methods study of educators' perspectives in the UK. Nurs. Health Sci. 2009; 12: 27-32.

[30] Morse JM. Approaches to qualitative-quantitative methodological triangulation. Nurs. Res. 1991; 40: 120-123. PMid:2003072

[31] Berelson B. Content analysis of communication research. NY: Free Press, 1952.

[32] Krippendorff K. Content analysis: An introduction to its methodology. London: Sage Publications, 1980.

[33] Lincoln YS, Guba EG. Naturalistic Inquiry. Beverly Hills: Sage Publications, 1985; 289-331.

[34] St John W, Flowers K. Working with families: from theory to clinical nursing practice. Collegian 2009; 16: $131-138$. http://dx.doi.org/10.1016/j.colegn.2009.04.001

[35] Bomar PJ. Promoting health in families: applying family research and theory to nursing practice. PA: Saunders, 2004. 